\title{
Stereotyped Phrenic Response to Laryngeal Afferent Volleys: The Mechanism and Anesthetic Sensitivity
}

\author{
YUJI SAKAI \\ Department of Pharmacology, Faculty of Medicine, \\ Saitama Medical School, Moroyama-Machi, Saitama, 350- \\ 04
}

\begin{abstract}
SakaI, Y. Stereotyped Phrenic Response to Laryngeal Afferent Volleys: The Mecharism and Anesthetic Sensitivity. Tohoku J. Exp. Med., 1988, 156, Suppl., 33-41_ The stereotyped reflex changes in phrenic discharge, produced by train(s) of electrical shocks to myelinated afferents in the internal branch of the superior laryngeal nerve (SLN), were studied in vagotomized cats and rabbits, mechanically ventilated with the mixture of oxygen and nitrous oxide. Single weak shocks caused a short latency $(4-5 \mathrm{msec})$ phrenic response, an excitation followed by a slight inhibition for $10 \mathrm{msec}$, which was repeatable at a rate of 200 $\mathrm{Hz}$ or more. Repeated weak shocks at a rate higher than $100 \mathrm{~Hz}$ or single stronger shocks caused a powerful inhibition with a limited duration (25-30 msec) of both the central inspiratory activity (CIA) and short latency response. This stereotyped inhibition, which was followed by a rebound excitation, could occur every $30-50 \mathrm{msec}$ with some reduction and was apparently associated with a decreased slope of integrated phrenicogram. During inhalation of halothane $(0.5-1.5 \%)$, the short latency phrenic response was reduced, while the stereotyped inhibition and the reduction of phrenic augmentation were markedly enhanced when the CIA was slightly depressed by halothane inhalation. Therefore, the stereotyped inhibition would represent an important mechanism of the reflex slowing of inspiration produced by myelinated laryngeal afferents.—-myelinated laryngeal afferents; short latency phrenic response; stereotyped inhibition; inspiratory slowing; susceptibility to halothane
\end{abstract}

The laryngeal reflexes are important in the regulation of breathing as well as in maintaining the upper airway patency (Boushey et al. 1972). A number of mucosal and joint capsular receptors in the larynx, most of which have myelinated afferent fibers, have been characterized and classified (Sampson and Eyzaguirre 1964; Storey 1968; Boushey et al. 1974; Widdicombe 1986). On the other hand, the relevent central integrative processes have been chiefly studied by electrical stimulation of the main afferent pathway from the larynx, the internal branch of the SLN (Biscoe and Sampson 1970a, b; Berger 1977; Sessle et al. 1978; McCrimmon et al. 1987). Single shocks to the SLN produce a stereotyped response of the phrenic nerve consisting of a short latency (disynaptic) excitation followed by a marked inhibition of the discharge (Iscoe et al. 1979). The inhibi- 
tion has been implicated in the inspiratory termination.

The principal aim in the present study is to characterize the phrenic responses evoked by laryngeal afferent shocks repeated at a rate higher than $100 \mathrm{~Hz}$. Some of the results were briefly reported elsewhere (Sakai 1987).

\section{Materials and Methods}

Experiments were performed on 15 cats of either sex $(2$ to $4 \mathrm{~kg}$ ) and ten male rabbits $(2.7$ to $3.5 \mathrm{~kg})$. Surgical procedures were done under a moderate depth of anesthesia with halothane (Fluothane, Takeda, Osaka). Tracheal, femoral arterial and venous cannulae were introduced. The phrenic nerve and the contralateral internal branch of the SLN were dissected and cut.

Immediately after halothane was discontinued, the animal was paralyzed with pancuronium bromide $\left(0.5 \mathrm{mg} / \mathrm{kg}\right.$ i.v.) (Mioblock ${ }^{\circledR}$; Sankyo, Tokyo) and was artificially ventilated with the respirator (SN-480-5, Shinano Seisakusho, Tokyo) connected to anethesia machine (Naito model, Shinei Industry, Tokyo). Throughout experiment, it was lightly anesthetized with the mixture of $55 \%$ nitrous oxide in oxygen. Experiments were usually begun one hour after the withdrawal of halothane. The muscular blockade was maintained by a continuous infusion of the solution of the blocker at a rate of $0.2 \mathrm{mg} / \mathrm{kg} / \mathrm{hr}$. Both carbon dioxide and oxygen levels in the end-expiratory gas were monitored (Respina 1H26, NEC Sanei, Tokyo) and the former was kept between $4.5 \%$ to $6.0 \%$. Both vagi were severed. The systemic blood pressure was also recorded with a pressure transducer (MPU0.5 , Nihon Kohden, Tokyo). The rectal temperature was maintained at $37-39^{\circ} \mathrm{C}$ with a thermister controlled heating lamp (ME-1059, ME Commercial, Tokyo).

Stimulation technics. The internal branch of the SLN was bipolarly stimulated by delivering squarewave pulses of $0.1 \mathrm{msec}$ or $0.05 \mathrm{msec}$ in width. The threshold intensity of single pulses for evoking phrenic responses was determined in each experiment. It was $0.1-0.15 \mathrm{~V}$ with 0.1 -msec pulses and $0.15 \mathrm{~V}$ with 0.05 -msec pulses. The uppermost intensity employed in this study was well below the uppermost for selective stimulation of myelinated laryngeal afferents, $0.4 \mathrm{~V}$ with $0.1-\mathrm{msec}$ pulses, as reported previously. Single pulses and single or paired trains of pulses $(50-200 \mathrm{~Hz})$, usually repeated at a rate of $4-8 \mathrm{~Hz}$ during central inspiratory periods, were generated by an assembly of stimulators and a phrenic processor similar to that described by Cohen (1968), with which the inspiratory gate signal was obtained.

Evaluation of the reflex responses. Reflex changes in efferent spike discharge of the phrenic nerve evoked by laryngeal afferent shocks, were evaluated on the peristimulus time histogram (PSTH), obtained by summing up for 100-300 computer sweeps (Signal Processor 7S06, NEC Sanei, Tokyo) with l-msec or 0.5 -msec bins. For this purpose, signals from the nerve were bipolarly recorded by conventional methods (1253A amplifier, NEC Sanei ; band pas $0.38-8 \mathrm{kHz}$ ) and further fed into a spike height discriminator (DSE-325P, Dia Medical System, Tokyo) to yield the synchronous pulses with a constant amplitude. These pulses were used to compute the PSTH of firing rate of the nerve. Synchronous pulses from the stimulator were employed to trigger the computer sweep. The onset of pulses for stimulation was usually delayed by 10 msec after that of computer sweeps.

The evoked discharge of the phrenic nerve was more precisely analyzed with a peristimulus time summation of efferent phrenic potentials (Fig. 1). In this case, the potentials, amplified through the same circuit, were summed up for 100-300 computer sweeps with 0.1 -msec or 0.2 -msec bins.

\section{RESUlts}

Electrical stimulation of the internal branch of the SLN in cats and rabbits 


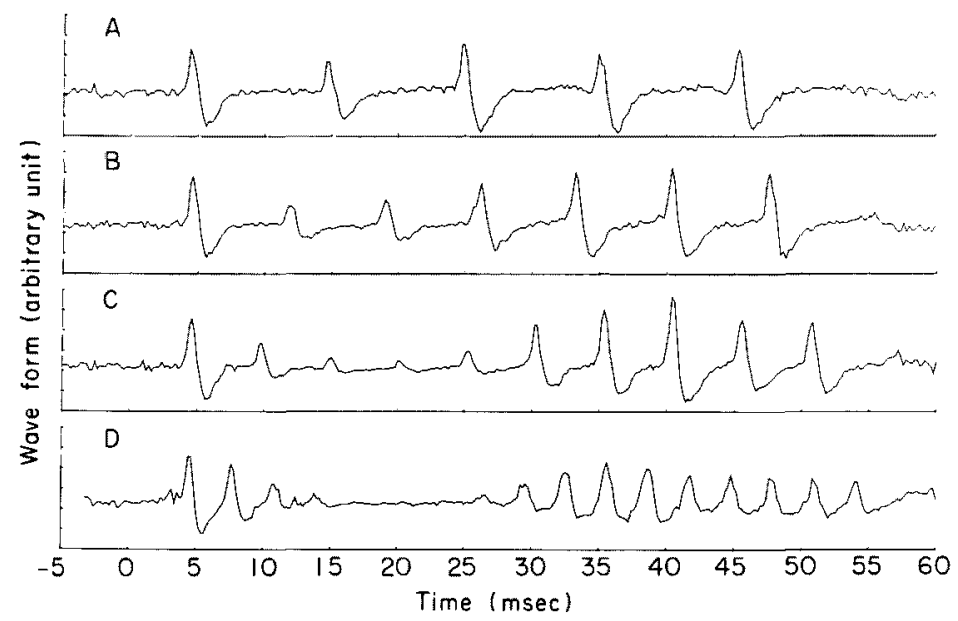

Fig. 1. Peristimulus time summation of efferent phrenic potentials in the cat. Each train of shocks $(0.05$ msec in width, $0.3 \mathrm{~V})$ started at 0 msec. Shocks repeated every $10 \mathrm{msec}(\mathrm{A}), 7 \mathrm{msec}(\mathrm{B}), 5 \mathrm{msec}(\mathrm{C})$ and $3 \mathrm{msec}(\mathrm{D})$, respectively. Number of computer sweeps: 100 .

produced both the excitation and inhibition of the phrenic nerve, which were shown by means of the peristimulus time summation of the efferent potentials (Fig. 1) as well as the PSTH of the spike discharge (Figs. 2, 4 and 5).

The short latency excitation and inhibition. Phrenic discharge with a peak

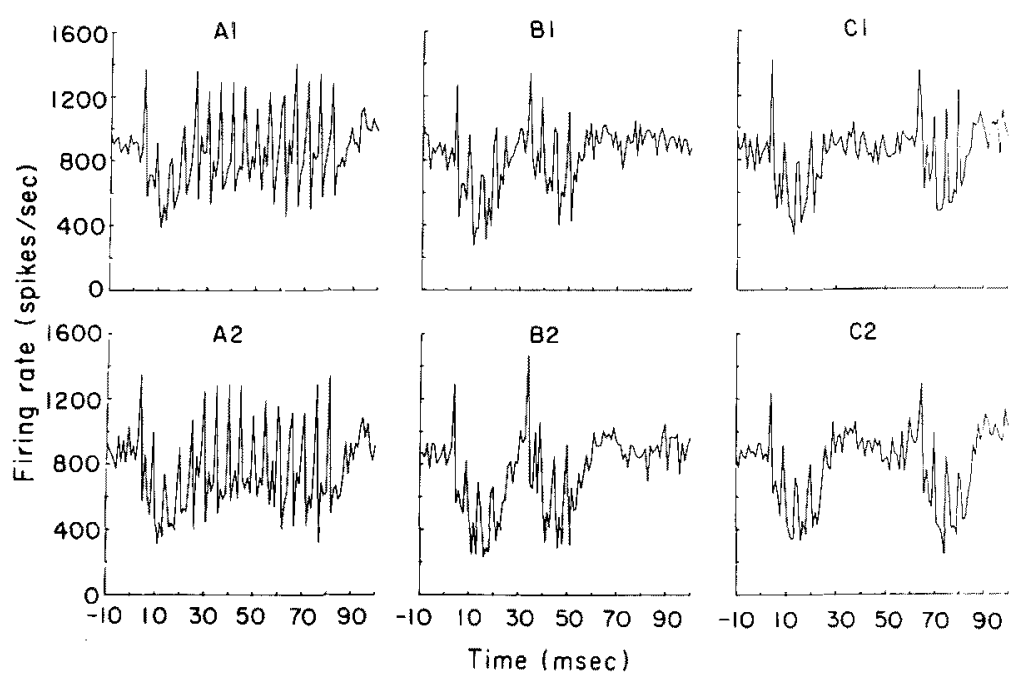

Fig. 2. PSTHs of phrenic discharge in the cat. Each PSTH is result of 100 summed cycles. A : A train of 16 shocks at $200 \mathrm{~Hz}$. B and $\mathrm{C}$ : paired trains of 4 shocks at $200 \mathrm{~Hz}$, at interval of $30 \mathrm{msec}$ and $60 \mathrm{msec}$, respectively. Intensity of stimuli $(0.05 \mathrm{msec}$ in width) $: 0.175 \mathrm{~V}(\mathrm{~A} 1, \mathrm{~B} 1$ and $\mathrm{Cl})$ and $0.2 \mathrm{~V}$ (A2, B2 and $\mathrm{C} 2$ ). 
latency of 4-5 msec was evoked by single shocks and the response could follo: each shock repeated even at $200 \mathrm{~Hz}$, though a period of its supression was seen for 25-30 msec after the first response (Fig. 1). In the PSTH, each excitatory response was followed by a mild-to-moderate inhibition lasting for $10 \mathrm{msec}$ or less, when either single shocks or a train of shocks at a rate of $100 \mathrm{~Hz}$ or less were delivered (Fig. 4).

The stereotyped inhibition. A long train of weak afferent shocks repeated at a frequency higher than $100 \mathrm{~Hz}$ always produced a marked suppression of the CIA as well as a reduction of the short latency evoked discharge after the first evoked discharge (Fig. $2 \mathrm{Al}$ and A2). The inhibition was most potent at 10-15 msec after the first shock and had a duration of $20 \mathrm{msec}$ or more. It was more marked and sustained by increasing the intensity of stimulation up to $0.4 \mathrm{~V}$ with $0.1-\mathrm{msec}$ pulses but the duration never exceeded $30 \mathrm{msec}$. This inhibition was followed by waves of the uninhibited or rather enhanced short latency excitation with an underlying less marked inhibition of the CIA continued as long as shocks were repeated. A rebound excitation of the CIA was apparent within $10 \mathrm{msec}$ following the last short latency excitation.

Therefore, the marked inhibition following the first evoked discharge had all characteristics of a stereotyped one and could be differentiated from the brief slight inhibition repeatable even at $200 \mathrm{~Hz}$. A brief train of a few weak shocks

A

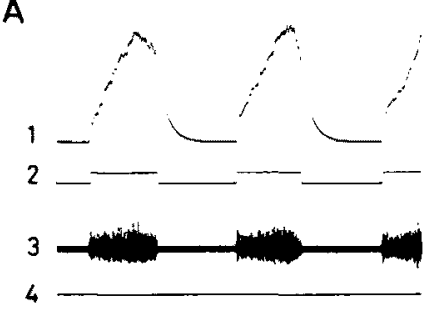

B

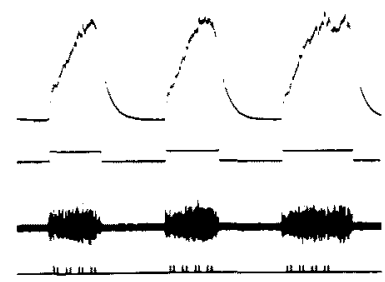

C

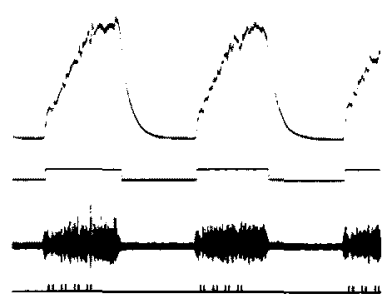

D

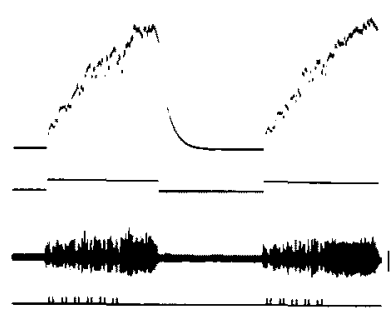

Fig. 3. Polygraph records in the cat. Traces in each records: the integrated phrenicogram (1), inspiratory gate signal (2), phrenic discharge (3) and stimulation signal (4). A : control record without stimulation. B to D : records during inspiratory paired trains (the interval of $40 \mathrm{msec}$ ) of afferent shocks at $200 \mathrm{~Hz}$ given at 8 times per second ; each train of 4 pulses $(0.05 \mathrm{msec}$ in width) of intensities, $0.15 \mathrm{~V}(\mathrm{~B}), 0.2 \mathrm{~V}(\mathrm{C})$ and $0.25 \mathrm{~V}(\mathrm{D})$, respectively. The slope of integrated phrenicogram $A$ to $D: 67^{\circ}, 65^{\circ}, 63^{\circ}$ and $56^{\circ}$, respectively. Vertical bar in D: $0.2 \mathrm{mV}$. Time scale : $2 \mathrm{sec}$. 
or a single shock of a stronger intensity could also evoke a more or less marked inhibition lasting for $15-25 \mathrm{msec}$ similar to the stereotyped one (Fig. 2B, C and Fig. 5). Such a stereotyped inhibition could be evoked every $30 \mathrm{msec}$ by each of paired brief trains of shocks, although the second one evoked 30-50 msec later was less in extent and duration (Fig. 2B, C and Fig. 5). A slight increase in the intensity of afferent shocks could only partly improve the second inhibition (Fig. $2 \mathrm{~B} 2$ and $\mathrm{C} 2$ ).

The reduction of the slope of integrated phrenicogram and the prolongation of the inspiratory time produced by laryngeal afferent shocks. Short trains of shocks repeated during inspiratory periods often caused a reduced slope of the integrated phrenicogram which was always associated with a more or less marked fragmentation of discharge, as an evidence of the stereotyped inhibition (Fig. 3C and D). In animals, which were being recovered from halothane anesthesia, however, a reduction of the slope was observed only when a nearly full extent of the stereotyped inhibition was evoked by each of trains of afferent shocks of a relatively stronger intensity. Furthermore, trains of shocks delivered during the incrementing phase of phrenic discharge almost always caused an increase in the inspiratory time. On the contrary, an inspiratory phrenic discharge was sometimes terminat-

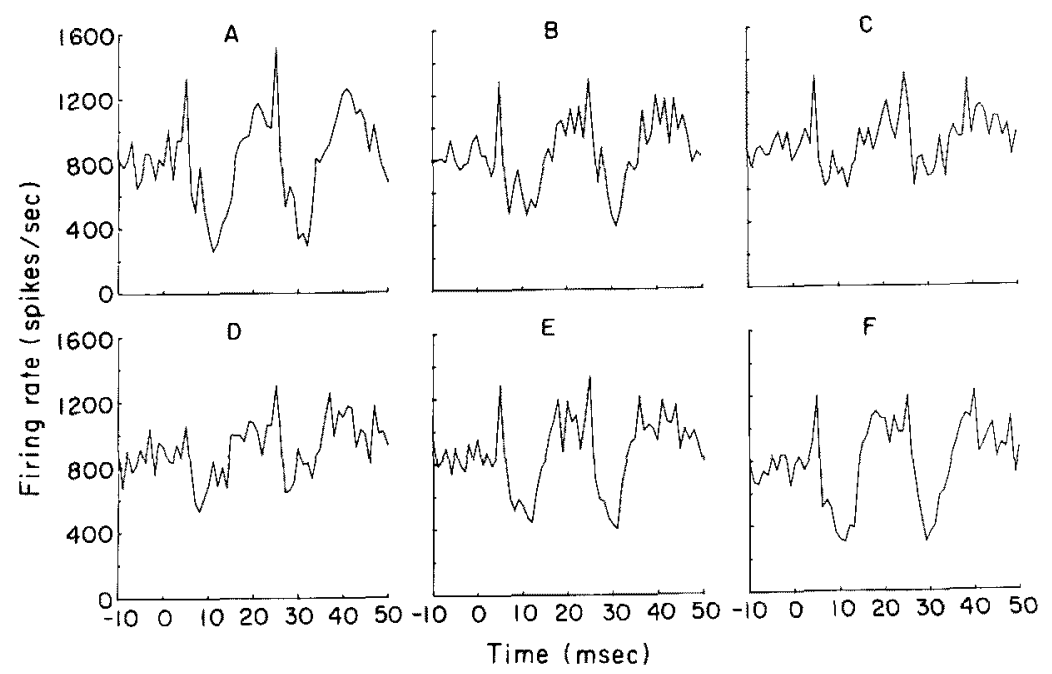

Fig. 4. Typical experiment in the rabbit showing a depressant effect of halothane on the short latency phrenic response to single shocks. Each PSTH is result of 70 summed cycles. Paired shocks $(0.1 \mathrm{msec}$ in width, $0.12 \mathrm{~V}$; at 0 and 20 $\mathrm{msec}$ in PSTH) are given once an inspiratory period $150 \mathrm{msec}$ after the onset. A : PSTH before halothane inhalation. B to D: PSTHs obtained during inhalation of halothane in concentration of $0.5,1.0$ and $1.5 \%$, respectively. Each halothane level held for $20 \mathrm{~min}$ and the corresponding PSTH was obtained between 15 and $20 \mathrm{~min}$. E and F : PSTHs obtained 25 and $45 \mathrm{~min}$ after the withdrawal of halothane. The end-expiratory level of carbon dioxide was maintained at $4.5-4.6 \%$ throughout this experiment. 
ed earlier, which occurred only when a train of shocks occasionally fell toward the end of discharge (Fig. 3B).

Effects of halothane on the phrenic responses to laryngeal afferent shocks. Inhalation of halothane caused a dose-dependent decrease in the short latency phrenic responses, both excitatory and inhibitory, evoked either by single shocks or by a train of shocks at a rate of $100 \mathrm{~Hz}$ or lower (Fig. 4B, C and D). This effect was observed even when the CIA was not significantly reduced. After the withdrawal of halothane, the recovery of the responses was very slow ( $\mathrm{E}$ and $\mathrm{F}$ ). In most cases, it took an hour for a complete recovery.

On the other hand, the stereotyped inhibition of a moderate-to-full extent, produced by brief trains of shocks at $200 \mathrm{~Hz}$, was always enhanced by inhalation of halothane (Fig. 5 B2 and B3). However, the weak inhibition evoked by afferent shocks with intensity slightly above the threshold seemed to be reduced, as shown by a less suppressed short latency excitation during the inhibition (B1). Both effects were observed even when halothane caused a slight decrease in the CIA. A greater reduction of the CIA under inhalation of $1.5 \%$ halothane was always accompanied by a decrease in the rebound excitation preceded by a more sustained stereotyped inhibition.

The decrease in the slope of integrated phrenicogram caused by inspiratory trains of afferent shocks, was also more marked during halothane inhalation.
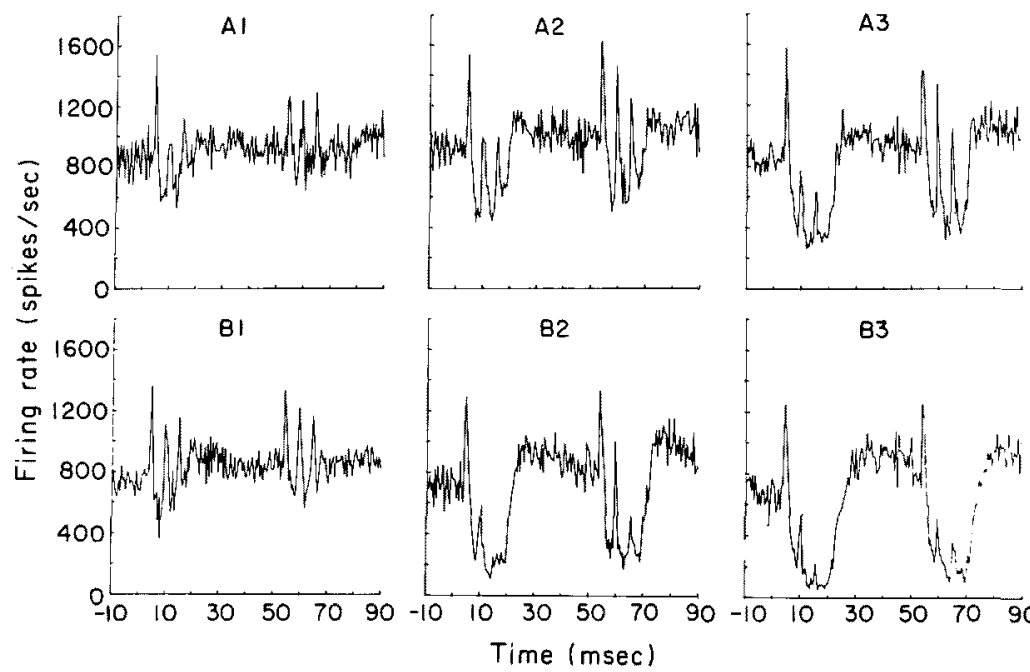

83

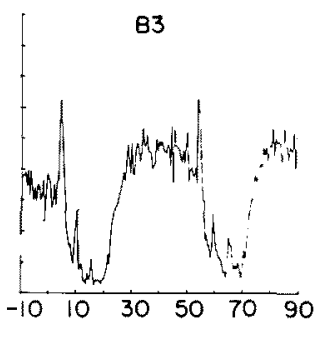

Fig. 5. Typical experiment in the cat showing an augmentation of the stereotyped inhibition with a slight suppression of the basal phrenic discharge during inhalation of $0.5 \%$ halothane. Width of stimuli $(0.15 \mathrm{~V}): 0.05 \mathrm{msec}$ for Al and $\mathrm{B} 1,0.06 \mathrm{msec}$ for $\mathrm{A} 2$ and $\mathrm{B} 2$, and $0.07 \mathrm{msec}$ for $\mathrm{A} 3$ and $\mathrm{B} 3$, respectively. Paired trains of 3 shocks at $200 \mathrm{~Hz}$ is given at 0 and 50 msec. Al, A2 and A3 : Control PSTHs before halothane inhalation. B1, B2 and B3: PSTHs obtained 15-25 min after the beginning of inhalation. Each PSTH is result of 100 summed cycles. 
Thus, a great reduction of the slope was produced by such trains of shocks of a weak intensity, which have failed to produce any significant change before inhalation of halothane. On the contrary, the reflex increase in the inspiratory time was rather reduced during the inhalation, while the reflex earlier termination of phrenic discharge tended to be enhanced.

\section{Disc USSION}

The present study successfully demonstrated that two distinct types of phrenic responses, both a short latency (disynaptic) excitation followed with brief slight inhibition and a long lasting powerful stereotyped inhibition, are evoked by weak electrical shocks, which may probably cause selective activation of myelinated laryngeal afferents and that both responses differ in their susceptibility to halothane. Such a distinction between the slight inhibition lasting less than $10 \mathrm{msec}$ and the stereotyped one following the evoked phrenic discharge has not been described (Iscoe et al. 1979). The former was always associated with the preceding excitation even when shocks were repeated at $200 \mathrm{~Hz}$ and both before and during inhalation of halothane. These observations exclude the possibility that the inhibition would be mediated by any inhibitory interneuron. Instead, the nature of the inhibition would be explained by assuming that a synchronous firing of a group of phrenic premotor neurons in response to laryngeal afferent activation is followed by a brief period of the reduced firing.

On the other hand, the stereotyped inhibition had many properties of a transsynaptic one, including a summation of train of afferent volleys at a rate higher than $100 \mathrm{~Hz}$, a limited duration (ca. 25-30 msec), an accompaying rebound excitation and a period of the reduced extent of the second inhibition lasting 2030 msec after the first one. A similar phrenic inhibition due to disfacilitation has been noted by Biscoe and Sampson (1970b). Therefore, it would be mediated by an unidentified group of inhibitory interneurons with a self limiting mechanism. Furthermore, the concurrent suppression of short latency evoked phrenic discharge indicates that premotor neurons will be subject to the stereotyped inhibition. However, it is uncertain that the source of their inspiratory activity is also affected.

The restricted duration of the stereotyped inhibition would be explained neither by a membrane property of inhibitory interneurons, since halothane will then rather reduce their repetitive firing due to its action on the membrane of neuronal somata and presynaptic terminals (Trudell 1977), nor by the CIA of premotor neurons which will be suppressed by this inhibition, because the duration was not so greatly increased in association with a considerable reduction of the CIA after hyperventilation (Sakai 1987). Thus, the remaining probable explanation for such a self limiting mechanism, that which is enhanced by halothane, would be a recurrent inhibitory feedback to the inhibitory interneurons. 
It is also noteworthy that both the short latency excitation and inhibition of the phrenic nerve by single shocks were reduced by halothane, possibly due to its action at the laryngeal afferent terminals on premotor neurons. The same should be also true at the terminals on the presumed interneurons mediating the stereotyped inhibition. In fact, the weak one evoked by a brief train of shocks of the intensity slightly above the threshold was rather reduced during inhalation of halothane.

The stereotyped inhibition may have a special role in the respiratory regulation. One would assume that it is a central mechanism for producing reflex inspiratory slowing, since it had a more close association with this effect than either with the inspiratory prolongation or with the earlier termination. A fragmentation of phrenic or diaphragmatic discharge has been shown in cats to occur at a rate of 10 times/sec during mechanical stimulation of the laryngeal mucosa (Boushey et al. 1972) or at a rate of 20-30 times/sec during purring (Remmers and Gautier 1972). The reflex effect, at least during purring, may be produced by the stereotyped inhibition of the CIA.

On the other hand, the short latency phrenic response to repetitive afferent shocks may have a role in modulating the high frequency oscillation of premotor discharge (Cohen 1973; Takano et al. 1987). Thus, the slight inhibition following a stereotyped inhibition during a long train of shocks at $200 \mathrm{~Hz}$ is supposed to be due to an interferrence of the excitatory laryngeal inputs with the high frequency oscillation.

The origin of myelinated laryngeal afferents, whose activation produces two types of phrenic responses, would be an interesting question. My recent study shows that trains of weak mechanical shocks of $2-3$ msec in duration delivered to the epiglottis mucosa can evoke similar phrenic responses as well as a group II afferent volley for $2-3 \mathrm{msec}$ in the internal branch of the SLN in response to each shock. Therefore, the phrenic responses to laryngeal afferent shocks described may well correspond to the reflex effects of mucosal mechanoreceptors of the larynx.

\section{Acknowledgments}

I thank Mr. K. Iijima for the construction of phrenic processor. The anesthesia machine for animals was kindly supplied by Shinei Industry Co.

\section{References}

1) Berger, A.J. (1977) Dorsal respiratory group neurons in the medulla of cat: Spinal projections, responses to lung inflation and superior laryngeal nerve stimulation. Brain Res., 135, 231-254.

2) Biscoe, T.J. \& Sampson, S.R. (1970a) Responses of cells in the brain stem of the cat to stimulation of the sinus, glossopharyngeal, aortic and superior laryngeal nerve. $J$. Physiol., 209, 359-373.

3) Biscoe, T.J. \& Sampson, S.R. (1970b) An analysis of the inhibition of phrenic 
motoneurones which occurs on stimulation of some cranial nerve afferents. $J$. Physiol., 209, 375-393.

4) Boushey, H.A., Richardson, P.S. \& Widdicombe, J.G. (1972) Reflex effects of laryngeal irritation on the pattern of breathing and total lung resistance. J. Physiol., 224, 501-513.

5) Boushey, H.A, Richardson, P.S. \& Widdicombe, J.G. (1974) The response of laryngeal afferent fibres to mechanical and chemical stimuli. J. Physiol., 240, 153-175.

6) Cohen, M.I. (1968) Discharge patterns of brain-stem respiratory neurons in relation to carbon dioxide tension. $J$. Neurophysiol., 31, 142-165.

7) Cohen, M.I. (1973) Synchronization of discharge, spontaneous and evoked, between inspiratory neurons. Acta Neurobiol. Exp., 33, 189-218.

8) Iscoe, S., Feldman, J.L. \& Cohen, M.I. (1979) Properties of inspiratory termination by superior laryngeal and vagal stimulation. Respir. Physiol., 36, 353-366.

9) McCrimmon, D.R., Speck, D.F. \& Feldman, J.L. (1987) Role of the ventrolateral region of the nucleus of the tractus solitarius in processing respiratory afferent input from vagus and superior laryngeal nerves. Exp. Brain Res., 67, 449-459.

10) Remmers, J.E. \& Gautier, H. (1972) Neural and mechanical mechanisms of feline purring. Respir. Physiol., 16, 351-361.

11) Sakai, Y. (1987) Pharmacology and physiology of the central mechanisms for respiratory reflexes with special reference to the reflex inhibition of phrenic discharge caused by shocks to the superior laryngeal nerve. Jpn. J. Pharmacol., 43, Suppl., $50 \mathrm{p}$.

12) Sampson, S. \& Eyzaguirre, C. (1964) Some functional characteristics of mechanoreceptors in the larynx of the cat. $J$. Neurophysiol., 27, 464-480.

13) Sessle, B. J., Greenwood, L.F., Lund, J.P. \& Lucier, G.E. (1978) Effects of upper respiratory tract stimuli on respiration and single respiratory neurons in the adult cat. Exp. Neurol., 61, 245-259.

14) Storey, A.T. (1968) A functional analysis of sensory units innervating epiglottis and larynx. Exp. Neurol., 20, 366-383.

15) Takano, K., Kato, F., Kimura, N., Nakagawa, T. \& Hukuhara, T., Jr. (1987) Stably discharging inspiratory unit activity in the brain stem with little correlation to phrenic high frequency oscillations in rabbits. In: Respiratory Muscles and Their Neuromotar Control, edited by G. Sieck, S.C. Gandevia \& W.E. Cameron, Alan R. Liss, Inc., New York pp. 67-71.

16) Trudell, J.R. (1977) A unitary theory of anesthesia based on lateral phase separations in nerve membranes. Anesthesiology, 46, 5-10.

17) Widdicombe, J.G. (1986) Reflexes from the upper respiratory tract. In: Handbook of Physiology, The Respiratory System, edited by A.P. Fishman, American Physiol. Soc., Bethesda, sect. 3, vol. II, pt 1, chap. 11, pp. 363-394. 